\title{
A CONSTRUÇÃO E TRANSMISSÃO DO CONHECIMENTO MATEMÁTICO SOB UMA PERSPECTIVA WITTGENSTEINIANA
}

\author{
Cristiane M. C. GotTSChalK*
}

\begin{abstract}
RESUMO: Com a "virada-lingüística" do final do século XIX, alguns filósofos, entre eles o austríaco Ludwig Wittgenstein, passam a considerar o papel das nossas expressões lingüísticas na constituição dos sentidos. Em particular, nas suas reflexōes sobre os fundamentos da matemática, Wittgenstein sugere que vejamos as proposiçōes matemáticas como regras a serem seguidas, atreladas a procedimentos e técnicas de natureza convencional, no interior de nossas formas de vida; sem que haja, portanto, uma realidade última e extralingüística que "fiscalize" a atividade matemática. Nesta nova abordagem, o pragmático passa a desempenhar um papel transcendental na transmissão e construção do conhecimento, contrapondo-se, assim, ao dogmatismo presente nas concepçôes epistemológicas anteriores e abrindo novas possibilidades para se pensar o ensino dessa disciplina.
\end{abstract}

Palavras-chave: Pragmática filosófica. Significado. Ensino de Matemática. Wittgenstein.

\section{THE CONSTRUCTION AND TRANSMISSION OF MATHEMATICAL KNOWLEDGE FROM A WITTGENSTEINIAN PERSPECTIVE}

ABSTRACT: With the "linguistic turn" of the end of the $19^{\text {th }}$ century, some philosophers, including the Austrian philosopher Ludwig Wittgenstein, began to consider the role of our linguistic expressions in the constitution of sense. Particularly in Wittgenstein's reflections on the foundations of mathematics, he suggests that we consider mathematical propositions as rules to be followed, attached

Doutora em Filosofia da Educação e professora do Programa de Pós-Graduação em Educação da Faculdade de Educação da Universidade de São Paulo (USP). E-mail: crisgott@usp.br 
to conventional procedures and techniques in our forms of life, without a finite and extra-linguistic reality that "supervises" mathematical activity, however. According to this new approach, the pragmatic dimension plays a transcendental role in the transmission and construction of knowledge, thus opposing the dogmatism present in the previous epistemological conceptions and providing new possibilities to conceive the teaching of this discipline.

Key words: Philosophical pragmatics. Meaning. Mathematics teaching. Wittgenstein.

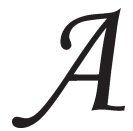

té o início do século $\mathrm{xx}$, matemáticos e físicos pareciam não duvidar de que haveria uma harmonia interna do mundo, expressa através de leis matemáticas, única realidade objetiva, única verdade que podemos atingir (Poincaré, 1995). Muitos dos grandes modelos pedagógicos propostos ao longo da história estão vinculados a essa idéia metafísica da matemática, que pressupõe a existência de significados matemáticos universais e absolutos passíveis de serem descobertos por meio de algum método. Para Platão, por exemplo, os objetos matemáticos estariam situados em um mundo celestial, e o papel do mestre seria conduzir o seu discípulo por meio de um diálogo, aproximando-o desses entes ideais, método que ficou conhecido como a maiêutica socrática. ${ }^{1}$ Já para Rousseau, o conhecimento matemático seria obtido no próprio mundo empírico, do mesmo modo que se procede nas ciências naturais: por meio de observações e experimentações. $\mathrm{O}$ preceptor de Emílio teria apenas que propiciar o necessário contato com a natureza e com as coisas, retardando ao máximo o conhecimento dos homens, educação por ele mesmo denominada de "negativa". ${ }^{2}$ Mais recentemente, o pragmatismo de Dewey procurou conciliar as perspectivas racional e empírica, ao considerar o conhecimento institucionalizado, organizado nas disciplinas escolares, e seus respectivos conceitos como sendo ferramentas úteis que, aplicadas à experiência do aluno, produziriam outras experiências cristalizadas em novos conceitos, à maneira do cientista que aplica leis para prever novos fatos da natureza. $\mathrm{O}$ método pedagógico por excelência seria, portanto, o método científico. ${ }^{3} \mathrm{O}$ professor deveria apresentar problemas para serem resolvidos pelos alunos, levando-os gradativamente a construir o conhecimento "recortado" pelo programa escolar.

Em todas estas tentativas de compreensão dos processos cognitivos e empíricos que permitiriam a construção e transmissão do 
conhecimento matemático, os fundamentos últimos da atividade matemática têm sido procurados em reinos ideais, empíricos ou mentais, pressupondo-se a autonomia e universalidade de seus significados. Afinal, dois mais dois deve ser igual a quatro em qualquer lugar do mundo! Assim, embora divirjam entre si quanto ao lócus natural dos fundamentos últimos da atividade matemática, comungam a crença de que a nossa linguagem teria uma função essencialmente comunicativa e descritiva dos significados que atribuímos às nossas experiências em geral. Metaforicamente, é como se a linguagem apenas revestisse de palavras esses significados, tendo a função exclusiva de "etiquetar" os objetos, nomeando-os. Este "modelo da vestimenta”, presente em diferentes epistemologias a que recorremos para fundamentar nossas práticas pedagógicas, também é denominado de concepção referencial da linguagem, uma vez que, deste ponto de vista, o significado da palavra seria o objeto a que ela se refere.

No Brasil, a maior parte das orientações pedagógicas para o ensino de matemática insere-se em maior ou menor grau nas concepçóes acima, produzindo determinadas imagens da atividade matemática, tais como: suas proposições decorrem de fatos da natureza, são desenvolvimentos naturais de estruturas cognitivas presentes potencialmente em toda criança, ou, ainda, de um ponto de vista mais pragmático, o aluno constrói o conhecimento matemático ao desenvolver estratégias que resolvem "situaçôes-problema"; por vezes, todas essas imagens convivem em um único documento, como é o caso do programa de ação educacional publicado pelo governo brasileiro em 1997, sob o nome de Parâmetros Curriculares Nacionais (PCN) (Brasil, 1997). Neste documento essas imagens estão inseridas em diferentes perspectivas construtivistas na educação, cujo denominador comum é a ênfase na atividade da criança que "constrói o seu próprio conhecimento". Dentre elas, predomina nos PCN a vertente cognitivista do construtivismo que proclama ter superado a oposição entre o empirismo e o idealismo característicos das concepçóes de ensino e aprendizagem anteriores: concebe as estruturas matemáticas como produtos de um determinado desenvolvimento mental do aluno, descrito pelas teorias psicogenéticas de Jean Piaget como se tratando de um processo natural de interação entre estruturas cognitivas e o meio físico e social. ${ }^{4}$ Em condiçôes propícias, toda criança percorreria os mesmos estágios, desde o sensório-motor até o pensamento hipotético-dedutivo, ou abstrato, característico da atividade matemática. O professor deve ser um "organizador da aprendizagem", permitindo, assim, que o 
aluno construa espontaneamente procedimentos e conceitos matemáticos. Portanto, também nesta concepção construtivista de ensino e aprendizagem, pressupõe-se uma autonomia dos significados matemáticos, como se estes apenas fossem revestidos pela linguagem matemática, perpetuando-se uma concepção referencial da linguagem subjacente a nossas práticas pedagógicas.

Nosso objetivo nesse trabalho é apontar para determinadas implicações educacionais, quando estamos aprisionados a essa concepção exclusivista e reducionista da linguagem, e sugerir outro modo de se ver as relações entre ensino e aprendizagem, ao considerarmos o papel peculiar que as proposições da matemática exercem nos diversos contextos em que são empregadas. Para isso, recorreremos a algumas reflexões do filósofo austríaco Ludwig Wittgenstein, considerado o maior representante da "virada-lingüística", ocorrida entre o final do século XIX e início do século XX. Boa parte delas diz respeito aos fundamentos do conhecimento matemático, com o objetivo de esclarecer algumas das questôes levantadas pelos filósofos da matemática, dentre as quais: $\mathrm{O}$ conhecimento matemático refere-se de fato a uma realidade objetiva, apreensível por meio de algum método? De onde viria a evidência de seus axiomas, definições e postulados? Como as expressões que decorrem dessas estipulações nos levam a construir os mais diversos equipamentos, pontes que não caem, foguetes e as mais altas tecnologias? E a intuição, teria algum papel no processo de construção desse conhecimento? Enfim, como a mente humana se torna capaz de possuir esse conhecimento? De onde viria a necessidade das proposições matemáticas?

Todas as tentativas de respostas a estas questôes têm levado a paradoxos e contradições insolúveis, desafiando ainda hoje a comunidade matemática e, simultaneamente, interessando ao educador, no sentido de que essa reflexão pode esclarecer a misteriosa conexão entre a atividade de ensinar e a constituição de significados, contribuindo para a compreensão de como se dá o processo de construção e transmissão do conhecimento matemático no contexto escolar.

\section{Algumas idéias de Wittgenstein}

Em suas observações sobre os fundamentos da matemática no início da década de 1930, Wittgenstein também se indagava sobre a 
natureza peculiar das proposições matemáticas, que pareciam desempenhar um papel muito diferente em relação às demais proposições da nossa linguagem ordinária. No entanto, ao invés de procurar responder diretamente às questôes acima, Wittgenstein ${ }^{5}$ levantou antes outra questão: Será que as palavras de nossa linguagem estão sempre se referindo a um fato empírico ou mental, como nos leva a crer uma concepção referencial da linguagem? Será que, ao afirmar que "um triângulo é um polígono de três lados" estou descrevendo algo do mesmo modo quando digo que "este papel sobre o qual estou escrevendo é branco"? A verdade dessas afirmações é igualmente sujeita à prova? De fato, posso verificar se esse papel à minha frente é branco ou não e atribuir um valor de verdade a essa afirmação; ou seja, verifico se é uma afirmação verdadeira ou falsa, recorrendo aos dados dos sentidos para fazer essa constatação. Mas será que a verdade da afirmação matemática também seria produto de algum tipo de experimentação?

Se a demonstração nos convence, também temos que estar convencidos, então dos axiomas. Não como o estamos de proposições empíricas; não é esse o seu papel. No jogo de linguagem, estão excluídos da verificação através da experiência. Não são proposições da experiência, mas princípios de juízo. (Wittgenstein, 1987, p. 73)

Vejamos em que sentido Wittgenstein faz as afirmaçóes acima. Ao investigar o funcionamento da nossa linguagem, o filósofo observou que utilizamos as proposições da matemática como normas: $2+2$ deve ser igual a 4! Essa proposição não é negada nem confirmada, é apenas uma regra de como proceder (um princípio de juízo). Permite-nos dizer que "se Maria escreveu e-mails para dois de seus amigos e no dia seguinte para outros dois, pelo menos quatro pessoas foram contatadas". Mesmo que, devido a um eventual problema da rede, uma dessas pessoas não tenha recebido o e-mail, este fato não invalida a proposição matemática de que dois mais dois é igual a quatro! É nesse sentido que Wittgenstein afirma que seguimos as proposições matemáticas "sem correr perigo de entrar em conflito com a experiência”, pois não são falseáveis por ela. Têm uma função normativa, e não descritiva. Não se referem a nada, apenas organizam a nossa experiência empírica. Também poderíamos imaginar que em uma comunidade onde esta regra não valesse, o enunciado acima não faria sentido. ${ }^{6}$ Para os membros dessa comunidade, por exemplo, 4 não seria o resultado de $2+2$, mas sim de $2+2+2$ ! 
Basta que contemples a figura

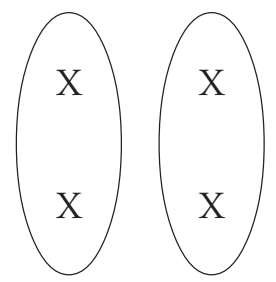

para ver que $2+2=4$. Então basta que vejas a figura

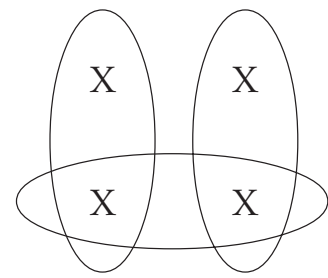

para ver que $2+2+2=4$. (Wittgenstein, 1987, p. 38 )

Os procedimentos que utilizamos para contar objetos dependem de nossas "formas de vida" (Lebensformen), expressão utilizada por Wittgenstein para designar nossos hábitos, costumes, ações e instituições que fundamentam nossas atividades em geral, envolvidas com a linguagem. Algumas destas ações empíricas se cristalizam na forma de regras e passam a traçar os limites do que faz e do que não faz sentido. Dizer que Maria enviou dois e-mails e depois mais dois, e que, portanto, três e-mails foram enviados por ela não faz sentido. "Dois mais dois é igual a quatro" é uma regra que seguimos independentemente do que ocorra de fato. "A inferência lógica é uma transição que se justifica, se segue um determinado paradigma, cuja legitimidade não depende de nada mais" (Wittgenstein, 1987, p. 66).

Em nossas formas de vida, as proposições matemáticas permitem ou proíbem certas inferências, somos autorizados por elas a passar de uma proposição empírica para outra, isto é, são consideradas, segundo Wittgenstein, como regras de substituição ou regras de inferência. Permitem-nos passar de uma proposição empírica para outra, estas sim com função descritiva e passíveis de verificação por meio de observaçôes e experimentos. 
Posso verificar se todos os amigos de Maria receberam os e-mails, mas não se "dois mais dois é quatro"! As regras não têm, elas próprias, algum significado, são apenas condiçôes de significado. Têm a função de paradigmas, modelos que seguimos para dar sentido à nossa experiência empírica.

Assim, a atividade matemática distingue-se radicalmente dos procedimentos empíricos: o cálculo não é um experimento, não é preditivo e tampouco a prova matemática se baseia em evidências empíricas (Wright, 1980; Gerrard, 1991). Exibir as soluções 2 e -2 que satisfazem a equação $\mathrm{x}^{2}=4$ não prova essa equação, do mesmo modo que os sons que ouço lá fora são indícios de que há carros passando na rua. A prova é dada por algum método de resolução desta equação, por exemplo, através da fórmula de Bháskara. Só então posso utilizar a palavra resulta, se conheço algum método de solução. Além do que, segundo Wittgenstein, o método geral de solução de uma equação não é um estratagema (um artifício) para se chegar às suas soluções, mas é em si próprio um esclarecimento da essência da equação. As conexões entre método e soluções são internas, necessárias. ${ }^{7}$ Portanto, não se trata de descobrir algo que já existia de alguma maneira; não há nada a ser descoberto antes que disponhamos de um método que nos permita procurar. Em outras palavras, descobrir as soluções de uma equação de segundo grau pressupõe o domínio de uma técnica, de um procedimento que independe do que existe, de possíveis "estados de coisas". Daí que a palavra "descobrir", em matemática, tenha um sentido muito diferente do utilizado nas ciências empíricas, o que por vezes passa despercebido para a maior parte dos pesquisadores da educação matemática, como veremos adiante em algumas das orientações metodológicas para o ensino e aprendizagem desse conhecimento presentes nos Parâmetros Curriculares Nacionais.

As proposições da matemática não se referem a algo a ser descoberto, não têm uma função descritiva, mas sim paradigmática, ou seja, são vistas por Wittgenstein como regras de como proceder. Regras que são expressas simbolicamente e que estão intrinsecamente envolvidas com determinadas atividades (um modo de agrupar, de fazer correspondências, de comparar etc.). Com o intuito de expressar melhor esta idéia de atividades reguladas, Wittgenstein introduz o conceito de "jogo de linguagem”, onde a matemática seria apenas um dos jogos de linguagem que fazem parte das nossas formas de vida, bastante distinto do jogo das 
A construção e transmissão do conhecimento matemático...

ciências empíricas. O acréscimo da palavra “jogo” ao conceito de linguagem não é fortuito; com isso Wittgenstein quer enfatizar o fato de que a linguagem não se reduz a um mero aglomerado de palavras: fragmentos do empírico, como açóes, estados mentais, determinados objetos etc., são incorporados pela linguagem e passam a ser utilizados como instrumentos lingüísticos, fazendo parte da constituição de seus significados e de suas conexões internas (Moreno, 2005).

Em sua obra mais conhecida da segunda fase de seu pensamento, as Investigações filosóficas, Wittgenstein sugere ao leitor que "não pense, mas olhe" como de fato utilizamos as nossas palavras nos diferentes jogos de linguagem em que estão inseridas, pois é no uso que fazemos delas, em meio às nossas atividades, que apreendemos os seus significados (Wittgenstein, 1999, $\$ \$ 43$ e 66). Critica, assim, a idéia de que o significado de uma palavra seja o objeto que ela supostamente substitui, seja este objeto de natureza ideal, mental ou empírica. Do mesmo modo que o significado de uma palavra, como mesa, é construído pelos diferentes empregos que fazemos dela em nosso dia a $\mathrm{dia}^{8}$ (escrevemos em cima dela, fazemos as nossas refeições etc.), assim também elaboramos nossos conceitos matemáticos, aplicando diversas regras ao longo deste processo. No decorrer desta atividade não há exploração e nem descoberta de um domínio objetivo. Mesmo a obtenção de um resultado, como na simples igualdade $12 \times 12=144$, só tem sentido se formos capazes de utilizar as regras de cálculo que relacionam os algarismos 1, 2 e 4 entre si. Em outras palavras, dizer que $12 \times 12$ tem como resultado 144 pressupõe o conhecimento de uma estrutura passível de ser representada (Wittgenstein, 1989, p. 150), constituída por regras de natureza convencional, imersas em nossas formas de vida.

Dizemos: "Se realmente vocês seguirem a regra da multiplicação, TEM QUE resultar o mesmo". Bem, se se trata apenas de um modo de falar, um tanto histérico, da linguagem universitária, não tem porque nos interessarmos muito. No entanto, se trata da expressão de uma atitude diante da técnica de cálculo, que se manifesta em nossa vida por toda parte. A ênfase do terque corresponde somente à inexorabilidade dessa atitude, tanto diante da técnica do cálculo, quanto diante das inumeráveis técnicas semelhantes. A necessidade matemática é apenas outra expressão do fato de que a matemática forma conceitos. E os conceitos servem para compreender. Correspondem a um tratamento determinado dos estados de coisas. A matemática forma uma rede de normas. (Wittgenstein, 1987, p. 67) 
Se a atividade matemática forma conceitos, isso significa que esta atividade não tem apenas um uso normativo, como também tem um uso empírico. Do mesmo modo que recorremos a uma régua para medir objetos empíricos, as proposiçôes matemáticas permitem que organizemos as nossas experiências de determinadas formas. Podemos usar os números naturais para contar quantos alunos há dentro de uma sala de aula (o que pressupõe o domínio da técnica da contagem), verificar se uma mesa mede tantos centímetros (há diferentes técnicas de mensuração) e, inclusive, concomitantemente a inúmeras outras técnicas, enviar um foguete à lua... No entanto, o uso empírico da matemática não comprova a suposta verdade de suas proposiçôes. Do mesmo modo que não tem sentido dizer que o metro-padrão de Paris mede um metro, analogamente, não tem sentido verificar o valor de verdade das proposições da matemática, uma vez que elas são o próprio padrão de correção. Estas e outras reflexões de Wittgenstein sobre a natureza do conhecimento matemático permitem-nos vislumbrar caminhos distintos dos procedimentos pedagógicos atuais ou, ao menos, relativizar algumas orientações para o ensino da matemática.

\section{As orientações construtivistas para o ensino de matemática}

O documento oficial do governo com as diretrizes pedagógicas para a educação brasileira, Parâmetros Curriculares Nacionais (PCN), como já dissemos, adotou prioritariamente uma concepção construtivista de ensino e aprendizagem para todas as disciplinas escolares. Como esse documento teve uma ampla divulgação e foi distribuído para todas as escolas públicas do país, julgamos que seja representativo da orientação atual para o ensino de matemática. Para uma das vertentes construtivistas presentes nesse documento, inspirada pelas teorias psicogenéticas do epistemólogo suíço Jean Piaget, haveria uma racionalidade natural no aluno, que o levaria a estabelecer estratégias próprias para a resolução de problemas, construindo, assim, por si só, novos conteúdos.

(...) muitas operações lógico-matemáticas já estão presentes na criança an-
tes da idade escolar sob formas elementares ou triviais, mas não menos sig-
nificativas. Mas acrescenta [Piaget], em seguida: Uma coisa é aprender na
ação e assim aplicar praticamente certas operaçōes, outra é tomar consciên-
cia das mesmas para delas extrair um conhecimento reflexivo e teórico, de 
A construção e transmissão do conhecimento matemático...

tal forma que nem os alunos nem os professores cheguem a suspeitar de que o conteúdo do ensino ministrado se pudesse apoiar em qualquer tipo de estruturas naturais. (Brasil, 1999, p. 146)

Essas idéias passam, então, a fundamentar algumas diretrizes construtivistas na educação, como vemos na seguinte passagem dos PCN:

(...) é fundamental não subestimar o potencial matemático dos alunos, reconhecendo que resolvem problemas, mesmo que razoavelmente complexos, ao lançar mão de seus conhecimentos sobre o assunto e buscar estabelecer relações entre o já conhecido e o novo (...). É relativamente recente a atenção ao fato de que o aluno é agente da construção do seu conhecimento, pelas conexões que estabelece com seu conhecimento prévio num contexto de resolução de problemas. (Brasil, 1998, p. 37)

Nesse sentido, são sugeridas ao professor atividades que auxiliem o aluno a construir determinados conceitos. Por exemplo, para que o aluno se aproprie inicialmente da idéia de número, são propostas atividades como as seguintes: levá-los a comparar duas coleções de objetos, a determinar a posição de um dado objeto numa linha, a identificar deslocamentos (avanços e recuos) numa pista graduada etc. (Brasil, 1997, p. 100). No entanto, frisam os PCN, essas atividades devem ser posteriores às hipóteses previamente formuladas pelos alunos. "É importante que o professor dê a seus alunos a oportunidade de expor suas hipóteses sobre os números e as escritas numéricas, pois essas hipóteses constituem subsídios para a organização de atividades" (idem, ibid.).

Em outra de suas passagens, os PCN propõem, por exemplo, que os professores apresentem "aos alunos 'situações-problema' cujas soluções não se encontram no campo dos números naturais, possibilitando, assim, que eles se aproximem da noção de número racional (...)" (Brasil, 1997, p. 83). Supõe-se, assim, que haja um desenvolvimento linear dessa racionalidade que deve ser levado em conta pelo professor para que ele possa "facilitar" o processo de construção de sentidos. Como se pode observar, nessa perspectiva o professor deve se limitar a escolher problemas que conduzam aos conteúdos visados, sem que haja uma interferência mais direta nesse processo.

No entanto, segundo uma concepção wittgensteiniana da natureza dos objetos matemáticos, não existiriam significados de número racional, ou de outro número qualquer, como os de irracional, imaginário, 
para os quais o aluno tenderia paulatinamente a ir resolvendo determinadas situaçôes problemáticas. Mas sim, para cada um deles, uma teoria dos números ("uma régua") que permite a criação de um novo uso do conceito de número ou, em termos wittgensteinianos, que autoriza o estabelecimento de uma nova conexão interna. Em outras palavras, uma nova aplicação é sugerida para o conceito de número, diferente das demais, mas que tem uma "semelhança de família" com as anteriores. Todas essas aplicações formariam uma rede de semelhanças que se sobrepõem umas às outras e se entrecruzam, semelhanças em grande e pequena escalas (Wittgenstein, 1999, \$66), como ocorre nos diferentes jogos que conhecemos - jogos de tabuleiro, de cartas, de bola etc. Consideramos todas essas diferentes atividades como exemplos de jogos. Podemos encontrar várias semelhanças entre elas, mas teremos dificuldades em localizar algo em comum a todas elas, que nos permita definir precisamente $o$ que é jogo. E, no entanto, isto não nos impede de empregar a palavra jogo a todas elas.

Não posso caracterizar melhor essas semelhanças do que por meio das palavras "semelhanças de família"; pois assim se sobrepõem e se entrecruzam as várias semelhanças que existem entre os membros de uma família: estatura, traços fisionômicos, cor dos olhos, andar, temperamento, etc., etc. - E eu direi: os "jogos" formam uma família.

Do mesmo modo formam uma família, p. ex., as espécies de números. Por que chamamos algo de "número"? Ora, talvez porque tem um-diretoparentesco com alguma coisa que até agora se chamou de número; e pode-se dizer que através disso adquire um parentesco com uma outra coisa que também chamamos assim. E alargamos nosso conceito de número do mesmo modo que, ao tecermos um fio, traçamos fibra por fibra. E a robustez do fio não consiste em que uma fibra qualquer perpasse toda sua extensão, mas em que muitas fibras se sobreponham umas às outras. (Wittgenstein, 1999, \$67)

Assim, para que o aluno se utilize de um novo emprego da palavra número, como, por exemplo, o de número racional, precisa aprender a transitar nesse novo espaço, a aplicar a nova "régua". Não tem sentido esperar que o aluno "descubra" o número racional, como se houvesse um caminho natural (e não convencional) que leve a ele, ou a qualquer outro conceito matemático, a partir de uma "situação-problema”. Um problema é um problema apenas quando a questão tem um 
sentido, e há um caminho apenas no sistema ${ }^{9}$ em que a questão está colocada. "Não se pode adivinhar como uma palavra funciona. É preciso que se veja a sua aplicação e assim se aprenda. A dificuldade é, porém, eliminar o preconceito que se opõe a esse aprendizado. Não se trata de nenhum preconceito tolo" (Wittgenstein, 1999, \$340).

No contexto escolar, cabe ao professor apresentar ao aluno as novas aplicações de um conceito. Aplicações, é importante que se diga, de natureza convencional, o que não significa que não se possa recorrer ao empírico para introduzir novas regras de uso. Mas, à diferença do pragmatismo de Dewey e outros similares (vertentes sociointeracionistas e antropológicas do construtivismo), esse empírico não é apenas contingente. Fragmentos da nossa experiência são recortados com a função de paradigma, ou seja, como modelos para o uso de nossas expressões lingüísticas. Nesse sentido, esses fragmentos passam a ter também a função de regra a ser seguida, do mesmo modo que um axioma da matemática ${ }^{10}$ (Moreno, 2005). Por exemplo, para introduzir o conceito de triângulo ou outro polígono qualquer, o professor faz desenhos dessas figuras na lousa, apontando para elas e dizendo: "isto é um triângulo" e assim por diante. Aquela figura desenhada na lousa não é $o$ significado de triângulo, mas passa a ter a função transcendental de mostrar ao aluno "o que é ser um triângulo", ou seja, é uma amostra de triângulo que cumpre a função de paradigma. Novas figuras e diferentes formatos de triângulo vão sendo apresentados (novos paradigmas), até que, a partir de um momento não previsível, esse aluno passa a reconhecer triângulos quaisquer, mesmo os que ainda não haviam sido apresentados pelo professor.

Mas como o professor interpreta a regra para o aluno? (Posto que alguma interpretação ele há de dar.) Bem, como, se não através de palavras e treinamento? (Essa é uma idéia importante.). E o aluno interioriza a regra (assim interpretada) quando reage a ela de tal e tal modo. Mas o importante é o seguinte: que essa reação, que nos garante a compreensão, pressuponha como contexto determinadas circunstâncias, determinadas formas de vida e de linguagem. (Da mesma forma que, sem rosto, não há expressão facial alguma.). (Wittgenstein, 1987, p. 47)

O que Wittgenstein procura ressaltar na passagem acima é que o ensino do significado de conceitos vem acompanhado de atividades intrinsecamente ligadas com a linguagem (Wittgenstein, 1999, \$23), 
ou seja, a compreensão se dá no interior de um jogo de linguagem. Em particular, a matemática pode ser vista como um desses jogos, sempre em mutação, pois também faz parte de uma forma de vida. Daí não ter sentido esperar que o aluno, independentemente de circunstâncias pragmáticas, ${ }^{11}$ apreenda por si só significados essenciais como, por exemplo, o que é número, ou o que é multiplicação, triângulo etc. A compreensão do conceito de número racional não se dá por aproximações sucessivas, como se fôssemos alcançando uma essência que se revela, comum a todas as aplicações desse conceito. Não há algo em comum a todas essas aplicações a ser apreendido pelo aluno, mas apenas semelhanças de família as mais variadas possíveis.

Assim, não há um "engate" de natureza causal entre "estruturas mentais" e os conteúdos escolares, ou entre "conhecimentos prévios" e o saber escolar, como sugerem algumas vertentes construtivistas, como se fosse possível ao professor reconhecer o estágio em que se encontram supostas atividades mentais de seus alunos para então fazer o "engate" com os "significados socioculturais refletidos nos conteúdos escolares". Esse processo progressivo de articulação de significados até um significado último é um mito essencialista. Em contraposição à idéia de um suposto "potencial matemático" que se desenvolveria em direção às essências dos conceitos matemáticos (como se houvesse objetos matemáticos preexistentes a alcançar), Wittgenstein nos mostra que o significado de uma palavra vai se tornando mais e mais complexo conforme seus usos vão se diferenciando.

Esta nova perspectiva (vinda da filosofia de Wittgenstein) sugere uma concepção de ensino e aprendizagem em que o papel do professor passa a ser ensinar significados através do uso que se faz deles em seus respectivos contextos lingüísticos. E aprender, por sua vez, é ser capaz de ver de outra maneira, sem que essa outra maneira seja uma "variação" de uma hipótese inicial do aluno. Em outras palavras, aprender é estar disposto a comparar seu modo usual de empregar certa imagem com outro (não importa que tipo de imagem seja).

Eu queria colocar esta imagem diante de seus olhos, e seu reconhecimento desta imagem consiste em que ele agora está inclinado a considerar um caso dado de outra maneira; ou seja, a compará-lo com esta série de imagens [por exemplo, a seqüência correta dos números naturais]. Modifiquei o seu modo de ver. (Dizem os matemáticos indianos: 'Veja isto!'). (Wittgenstein, 1999, $\$ 144)$ 
Portanto, não se trata da evolução natural de uma "hipótese" ainda precária para uma afirmação que se aproxima paulatinamente de verdades preexistentes, mas da apresentação ao aluno de um outro modo de ver ("Veja isto!"). Exigir do professor que não intervenha no processo de aprendizagem - pois, caso contrário, estaria "conduzindo" o aluno e assim impedindo uma "aprendizagem significativa" - é desobrigálo de apresentar essas novas maneiras de ver, as quais não decorrem naturalmente das hipóteses do aluno. São convenções.

Um símbolo matemático é vazio, não há uma necessidade lógica que nos obrigue a uma determinada direção, como, por exemplo, a de um desenvolvimento natural e espontâneo de supostas estruturas cognitivas. O que vai nos dar a essência de um conceito matemático é a sua aplicação, pois é no momento do uso do conceito que nos conectamos com toda a sua gramática. Só adquire sentido para o aluno, portanto, ao aplicá-lo, o que envolve técnicas que são aprendidas e não de alguma forma intuídas ou descobertas. Nesse sentido, é fundamental a atuação do professor, pois é ele que pode libertar o aluno de determinadas imagens, ${ }^{12}$ introduzindo novos pontos de vista: outros empregos de conceitos já conhecidos como também apresentando novos conceitos. Uma vez que as atividades e os procedimentos que acompanham o uso dos símbolos matemáticos são de natureza convencional, não cabe esperar que o aluno adivinhe como se dá uma nova aplicação de um determinado conceito ou proposição da matemática (ou, em termos construtivistas, que “construa o seu próprio conhecimento"); mas sim, como enfatiza Wittgenstein, possibilitar que o aluno veja essa nova aplicação como operada pelo professor. Nesse sentido, estamos nos aproximando de uma resposta para a questão educacional apresentada anteriormente, a saber, como se dá a conexão entre os conceitos de ensino e de significado.

\section{Ensino e significado}

Vimos até aqui que não há algo a ser transmitido que poderia ser de alguma forma intuído ou descoberto pelo aluno, independentemente da linguagem e das atividades com ela envolvidas, como se o pensamento antecedesse a expressão lingüística, ou como se as palavras tivessem apenas a função de nomear significados fixos e de algum modo já presentes (virtualmente) na experiência da criança. Assim, ao se romper com uma visão essencialista da linguagem, a de que haveria um 
significado extralingüístico a ser apreendido pelo aluno (e este é que seria o preconceito nada tolo a que se refere Wittgenstein), resgata-se a responsabilidade do professor em introduzir o aluno a alguns dos "jogos de linguagem” da matemática. No entanto, resta esclarecer como adquirimos a convicção com que enunciamos as proposiçôes matemáticas ("É claro que dois mais dois é igual a quatro!"). Wittgenstein vai dissolver este enigma também de uma maneira muito simples, a saber, basta observar os modos pelos quais somos inseridos em nossas práticas cotidianas:

Contam-me, por exemplo, que alguém escalou esta montanha muitos anos atrás. Sempre indago pela confiabilidade do contador dessa história, ou se a montanha existia? Uma criança aprende que há informantes confiáveis e não confiáveis muito mais tarde do que aprende fatos que lhe são contados. Não aprende de maneira alguma que aquela montanha existiu por muito tempo: ou seja, essa questão não se levantava absolutamente. Essa conseqüência é "engolida", digamos, juntamente com oquê ela aprende. (Wittgenstein, 1979, \$143)

Assim, há conteúdos que não são aprendidos, no sentido canônico de aprendizagem. A existência da montanha não é colocada em questão, é simplesmente pressuposta no discurso lingüístico ou nas atividades em que estes conteúdos estão envolvidos: "As crianças não aprendem que os livros existem, que as poltronas existem etc. etc. - elas aprendem a buscar livros, a sentar em poltronas etc. etc.” (idem, ibid., \$476).

Da mesma forma que em seu cotidiano a criança incorpora crenças através de relatos e ações ("essa cadeira existe" ou "a montanha já existia há muitos anos atrás”), a autoridade do professor é veículo de outras crenças, que não são aprendidas pelo aluno, mas que são os pressupostos para que ele aprenda. É o modo como o professor expóe sua disciplina que imbui novas crenças, as quais se tornarão condições de significado para o conhecimento a ser transmitido, construindo-se, assim, nossas certezas primeiras, inquestionáveis. "Ninguém, a não ser um filósofo, diria 'Sei que tenho duas mãos'; mas alguém poderia decerto dizer: 'Sou incapaz de duvidar de que tenho duas mãos'” (idem, $1981, \$ 405)$.

Adquirimos nossas certezas: sabemos que a cadeira à nossa frente existe e não temos dúvida de que possuímos duas mãos. São essas certezas, por exemplo, que nos permitem atribuir sentido às expressóes 
A construção e transmissão do conhecimento matemático...

lingüísticas “junte as mãos!”, ou então "de que material é feita essa cadeira?”, e assim por diante. No entanto, outra coisa é a apresentação explícita das certezas matemáticas pelo professor, como os axiomas da geometria euclidiana e as definições de determinados conceitos, que não fazem parte do cotidiano do aluno. Por que, então, o aluno se convence imediatamente destas coisas? "Bem, essas leis se acomodam perfeitamente ao uso da linguagem que lhe resulta tão familiar" (Wittgenstein, 1987, p. 73). Vejamos o que Wittgenstein quer dizer com isso através de um exemplo banal, mas bastante ilustrativo, que é o da formação do conceito de triângulo na geometria, já presente de outros modos na linguagem cotidiana.

Dependendo do contexto em que é dita, a palavra "triângulo" pode ser compreendida como um instrumento musical ou mesmo como um sinal de trânsito. Já no contexto de uma aula de geometria, esse mesmo termo é introduzido com um significado radicalmente diferente, pois agora é todo um sistema geométrico que passa a lhe atribuir um novo significado. Como então responder à questão acima? De onde vem a suposta evidência dos axiomas e postulados desse sistema? Poderíamos pensar que haveria certa "semelhança de família" entre o uso geométrico dessa palavra e os seus significados já construídos anteriormente (conhecimento prévio do aluno), suficiente para que o aluno "construa" por si só o conceito de triângulo na geometria. Aparentemente, estaríamos confluindo para uma posição muito próxima da orientação construtivista de que esses significados se encadeiem de modo que o aluno vá se aproximando do conceito geométrico em questão, da essência do que é ser triângulo. No entanto, como vimos, não há algo extralingüístico para o qual convergem os significados dessa palavra. Nossos conceitos têm uma vagueza intrínseca e é apenas na sua aplicação em determinadas circunstâncias que adquirem significados. Além do que, são diferentes os usos que fazemos de uma palavra: ora descritivo, ora normativo.

Em particular, nesse novo contexto (em uma aula de geometria), o uso que se faz agora da palavra "triângulo" não é mais empírico, mas sim normativo. Um triângulo deve ter três lados, seus ângulos internos devem totalizar $180^{\circ}$ etc. A introdução desse novo modo de aplicar essa palavra é feita através de textos de livros didáticos ou por intermédio da autoridade de um professor, e não medindo os ângulos de certa quantidade de triângulos até que o aluno chegue "sozinho" à conclusão de que a soma dos ângulos internos de um triângulo é sempre 
$180^{\circ}$. Esta afirmação resulta de uma demonstração matemática e não de uma experimentação empírica. ${ }^{13}$ Além do que, o tom normativo em que são proferidas essas certezas matemáticas remete o aluno ao pano de fundo de todas as suas antigas e bem construídas certezas, como, por exemplo, a de que seu nome é João, de que ele próprio e os objetos à sua volta existem, de que os rios e montanhas de que falam os livros existem há muito tempo, de que tem duas mãos e assim por diante.

Dizer que "a soma dos ângulos internos de qualquer triângulo deve ser $180^{\circ}$ " passa a ser uma das regras a serem seguidas para se aplicar a palavra triângulo no contexto de uma aula de geometria. A própria definição "triângulo é um polígono de três lados" também diz o que é ser triângulo na geometria euclidiana. Enfim, há um conjunto de regras, tais como definições e demonstrações matemáticas, envolvendo técnicas e procedimentos com réguas, compassos, transferidores etc., que vão permitindo ao aluno operar simultaneamente não apenas com diferentes triângulos, mas também com quadrados, hexágonos, círculos etc. Ser um triângulo implica não ser um quadrado ou qualquer outro polígono com um número de lados maior que três, não ser um círculo, e assim por diante. "Quando começamos a acreditar em algo, o que acreditamos não é uma simples proposição, é todo um inteiro sistema de proposições. (A luz ilumina gradualmente o todo)" (Wittgenstein, 1979, \$141).

Desse modo, imagens, palavras e modos de operar com elas são apresentados ao aluno, lembrando que tanto uma imagem como uma palavra, por si só, são símbolos vazios se não forem acompanhados por alguma técnica que permita seu emprego.

Como ensinamos, pois, a inferir? Ou não ensinamos? A criança sabe que da dupla negação segue-se a afirmação? - E como se convence disso? Com certeza mostrando-lhe um processo (uma dupla inversão, um duplo giro de $180^{\circ}$, e coisas semelhantes) que ela adota como imagem da negação. (Wittgenstein, 1987, p. 11)

Por meio de comparações, relações internas entre conceitos são estabelecidas. Recorre-se a determinados processos e atividades que cumprem uma função paradigmática: é assim que operamos. Em outras palavras, por meio de exemplos, predispóe-se o aluno a ver como. O professor apresenta-lhe outros pontos de vista, outras formas de ver, com o objetivo de persuadi-lo a aceitá-los. "Toda explicação tem seu fundamento no treino. (Os educadores deviam lembrar-se disto.)” (idem, 1981, \$419). 
Através da autoridade do professor (e dos textos que ele indica), o aluno toma para si pressupostos implícitos que são determinantes para o aprendizado de outros conteúdos. Daí concluirmos que os conteúdos não são meros meios para o desenvolvimento intelectual do aluno e, tampouco, ferramentas úteis para a produção de novas experiências (como afirmava Dewey), mas a condição para que o aluno possa continuar aprendendo. Esperar que os alunos, através da ação, "deduzam" o significado de um conceito, como sugerem os PCN, é apoiar-se numa concepção referencial da linguagem, ou seja, é acreditar que haja um significado essencial do conceito, passível de ser descoberto, como ocorre nas ciências empíricas, onde o cientista procura estabelecer relações externas entre os fatos, ou seja, tem como pretensão a descoberta de conexões causais entre eles. No entanto, segundo Wittgenstein, o matemático não descobre, apenas inventa. As relações que são estabelecidas são internas, gramaticais: são ligações de sentido. Inventam-se formas que atribuem determinados sentidos ao mundo. "É evidente que a gramática da palavra 'saber' goza de estreito parentesco com a gramática das palavras 'poder', 'ser capaz'. Mas também com a gramática da palavra 'compreender'. ('Dominar' uma técnica.)” (Wittgenstein, 1999, \$150).

\section{Uma perspectiva pragmática de ensino}

Como vimos, as relaçôes entre ensino e significado transcendem em muito as possíveis manifestações mentais que eventualmente acompanham o aprendizado. De uma perspectiva $\operatorname{pragmática~}^{14}$ do ensino e da aprendizagem no contexto escolar, é essencialmente por intermédio do professor que novos paradigmas são introduzidos e passam a ser as condições de sentido para a atividade matemática, e não que os significados sejam construídos naturalmente pelos alunos a partir de situações empíricas, como pressupõem a maioria das orientações pedagógicas em vigor para o ensino de matemática. São escolhas que envolvem valores e respeito a uma herança cultural a ser transmitida, da qual a matemática faz parte desde seus primórdios.

Compreender não é um processo mental, mas ser capaz de seguir uma regra, ou seja, é dominar uma técnica. A partir daí, espera-se que o aluno passe a proceder corretamente (isto é, como a comunidade referente ao jogo de linguagem em questão assim o espera). A compreensão depende de um ensino de regras, conceitos e procedimentos e, 
fundamentalmente, de um treino, para que o aluno comece, a partir de um determinado momento não previsível a priori, a "fazer lances" no jogo de linguagem no qual está sendo introduzido, inclusive aplicando-o a situações empíricas. Assim, de uma perspectiva pragmática de ensino, motivar o aluno, quando se introduz um novo conceito, é diferente de esperar que o próprio aluno, a partir de uma "situação-problema", "construa” o conceito em questão. Só depois de apresentados os paradigmas para que o aluno possa "jogar" é que tem sentido apresentar desafios na forma de problemas ou partir de situações empíricas.

Enfim, o uso empírico das proposições da matemática não prova a existência de uma estrutura a priori expressa através delas, como pensava Poincaré e outros matemáticos, passível de ser descoberta por meio de algum método, procurando-a em um mundo ideal, seja ele transcendental ou mental, ou mesmo supostamente abstraído do empírico. Segundo Wittgenstein, a essência dos conceitos e proposições da matemática é de natureza convencional e pragmática. Daí que para sua transmissão e construção seja fundamental o ensino de técnicas e procedimentos que foram sendo inventados pelos matemáticos ao longo dos tempos, e não descobertos como sugerem as práticas pedagógicas atuais.

\section{Recebido em dezembro de 2007 e aprovado em março de 2008.}

\section{Notas}

1. Platão escreveu diversos diálogos que ficaram conhecidos como Diálogos platônicos, nos quais introduz muitas de suas idéias através do personagem de Sócrates. No diálogo Menon, Sócrates pede que chamem um escravo que nunca havia recebido aulas de geometria e, por meio de perguntas bem conduzidas, faz com que o escravo deduza o teorema de Pitágoras. Com isso, prova sua teoria da reminiscência, segundo a qual conhecer é recordar, isto é, "reconhecer o que a alma tem em si por tê-lo contemplado antes de vir habitar o corpo" (Mondolfo, 1964, p. 165).

2. A seguinte passagem do Emílio de Rousseau esclarece em que sentido o filósofo afirma que sua educação é negativa: “(...) a primeira educação deve ser puramente negativa. Consiste não em ensinar a virtude ou a verdade, mas em proteger o coração contra o vício e o espírito contra o erro. Se pudésseis levar vosso aluno são e robusto até a idade de doze anos sem que ele soubesse distinguir a mão esquerda da direita, desde vossas primeiras liçôes os olhos de seu entendimento se abririam para a razão; sem preconceitos, sem hábitos, ele nada teria em si que pudesse obstar o efeito de vossos trabalhos. Logo se tornaria em vossas mãos o mais sábio dos homens e, começando por nada fazer, teríeis feito um prodígio de educação" (Rousseau, 1999, p. 91).

3. Todavia, à diferença do cientista que tem um olhar prospectivo, o professor deveria ter um olhar retrospectivo, pois teria que identificar na experiência da criança os fatos, as atitudes

Cad. Cedes, Campinas, vol. 28, n. 74, p. 75-96, jan./abr. 2008 
e as motivações comuns a ela e aos cientistas que formularam os conhecimentos almejados pelo professor (Dewey, 1978).

4. No interior do próprio construtivismo já se faz críticas a alguns dos pressupostos da vertente cognitivista, apontando-se para outros modos de se considerar a construção dos significados matemáticos. Dentre elas, as formuladas pela vertente construtivista denominada antropológica, inspirada nas teorias epistemológicas de Habermas e Rorty, inseridas na "virada-lingüística" (Cobb, 1996, p. 153-180).

5. Estaremos nesse trabalho considerando os escritos do "segundo Wittgenstein", ou seja, sua obra após o Tractatus Logico-Philosophicus.

6. Em uma escola indígena brasileira, um índio faz o seguinte relato a um pesquisador de sua cultura: “(...) quando perguntamos quantas folhas de manga têm (ele desenha três folhas de manga na lousa, dizendo que deveríamos pensá-las iguais em tamanho e cor), as pessoas do nosso povo diria que tem uma. E, então, se juntamos uma pedra e um pedaço de pau, quantos objetos temos ao todo? Temos três, não?” (Domite, 2002, p. 2). Os modos como agrupamos os objetos dependem de um treino, e mesmo a contagem desses objetos é uma técnica aprendida, que pode variar de uma forma de vida para outra (Gottschalk, 2004, p. 330).

7. Diferentemente das relações externas, empíricas, contingentes. Os sons que ouço lá fora podem ser de buzinas, ou apenas o barulho do motor dos carros. Quanto mais indícios tenho, mais confirmo a minha hipótese de que há carros passando na rua. Do mesmo modo, as proposições das ciências empíricas que descrevem nossa experiência são mais ou menos confirmadas, ou, como diz Wittgenstein, são sujeitas à prova recorrendo-se a observações e experimentaçóes.

8. Em uma outra forma de vida esses objetos que chamamos de mesa poderiam ser utilizados de outros modos, por exemplo, em rituais de oferecimento, ou mesmo nem seriam conhecidos.

9. “Sistema” entendido aqui como o conjunto de regras de natureza convencional que atribuem sentido aos conteúdos da questão.

10. Essas idéias de Wittgenstein sobre o papel do pragmático na constituição dos sentidos foram sistematizadas por Arley Ramos Moreno, em sua obra Introdução a uma pragmática filosófica (2005), sugerindo uma nova epistemologia de inspiração wittgensteiniana, batizada pelo autor de "pragmática filosófica".

11. Estamos empregando o termo pragmático num sentido distinto do empírico, ou seja, o pragmático refere-se a açóes e procedimentos de natureza convencional, imersos em nossas formas de vida, e com função normativa.

12. Imagens, no sentido de aplicaçôes usuais do conceito, consideradas dogmaticamente.

13. Esse modo empírico de se concluir a proposição matemática de que "a soma dos ângulos internos de um triângulo é $180^{\circ}$ ", frequentemente, apenas confunde o aluno, que na maior parte das vezes encontra apenas medidas que, somadas, dão um valor próximo de $180^{\circ}$, não correspondendo em absoluto à expectativa do professor de que "provem" a proposição acima, através dessa experimentação.

14. O termo "pragmático" está sendo utilizado aqui no sentido dado por Moreno (2005), em sua obra Introdução a uma pragmática filosófica, distinto do pragmatismo americano de Dewey e de outros filósofos, uma vez que, para o autor, fragmentos do empírico não seriam contingentes, mas exerceriam uma função transcendental, paradigmas do que é ser algo. 


\section{Referências}

AGOSTINHO. O mestre. São Paulo: Landy, 2002.

BLACK, M. El laberinto del lenguaje. Califórnia: Monte Ávila, 1969. cap. 4.

BRASIL. Ministério da Educação. Secretaria de Educação Fundamental. Parâmetros curriculares nacionais: ( $1^{\mathrm{a}}$ a $4^{\mathrm{a}}$ séries). Brasília, DF: MEC/ SEF, 1997. v. 1, v. 3.

BRASIL. Ministério da Educação. Secretaria de Educação Fundamental. Parâmetros curriculares nacionais: $\left(5^{\mathrm{a}}\right.$ a $8^{\mathrm{a}}$ séries). Brasília, DF: MEC/ SEF, 1998. v. 1, v. 3.

BRASIL. Ministério da Educação. Secretaria da Educação Media e Tecnológica. Parâmetros curriculares nacionais: ensino médio. Brasília, DF: MEC/SEMT, 1999. pt. 3. Ciências da natureza, matemática e suas tecnologias. v. 1 , v. 3

$\mathrm{COBB}, \mathrm{P}$. Perspectivas experimental, cognitivista e antropológica em educação matemática. Zetetiké, Campinas, v. 4, n. 6, p. 153-180, 1996.

DEWEY, J. Vida e educação. São Paulo: Melhoramentos, 1978.

DOMITE, M.C. Etnomatemática e sua teoria: teoria da etnomatemática? In: CONGRESSO INTERNACIONAL DE ETNOMATEMATICA, 2., 2002, Ouro Preto. Anais... Ouro Preto, 2002.

GERRARD, S. Wittgenstein's philosophies of mathematics. Synthese, Dordbrecht, n. 87, p. 125-142, 1991.

GOTTSCHALK, C.M.C. A natureza do conhecimento matemático sob a perspectiva de Wittgenstein: algumas implicações educacionais. Cadernos de História e Filosofia da Ciência, Campinas, v. 14, n. 2, p. 305-334, jul.-dez. 2004.

MACMILLAN, C.J.B. How not to learn: reflections on Wittgenstein and learning. In: Smeyers, P.; Marshall, J.D. (Ed.). Philosophy and education: accepting Wittgenstein's challenge. Dordbrecht: Kluwer, 1995. v. 6, p. 161-169. 
MONDOLFO, R. O pensamento antigo (história da filosofia grecoromana). São Paulo: EDUsP; Mestre Jou, 1964. 2v.

MORENO, A.R. Wittgenstein: através das imagens. Campinas: UNICAMP, 1995.

MORENO, A.R. Introdução a uma pragmática filosófica. Campinas: UNICAMP, 2005.

POINCARÉ, H. O valor da ciência. Rio de Janeiro: Contraponto, 1995.

PUTNAM, H. O que é inato e por quê. In: Piaget, J. et al. Teorias de linguagem, teorias da aprendizagem: o debate entre Jean Piaget e Noam Chomsky. Trad. Álvaro Cabral. São Paulo: Cultrix; EDUsP, 1983. p. 356-381.

ROUSSEAU, J.-J. Emilio. Trad. Roberto Leal Ferreira. São Paulo: Martins Fontes, 1999.

RYLE, G. Teaching and training. In: Peters, R.S. The concept of education. London: Routledge, 1968.

WITTGENSTEIN, L. On certainty. Oxford:Blackwell, 1979.

WITTGENSTEIN, L. Fichas (Zettel). Lisboa: Edições 70, 1981.

WITTGENSTEIN, L. Observaciones sobre los fundamentos de la matemática. Madri: Alianza, 1987.

WITTGENSTEIN, L. Philosophische Bemerkungen. Frankfurt am Main: Suhrkamp, 1989.

WITTGENSTEIN, L. Investigações filosóficas. Trad. José Carlos Bruni. Rio de Janeiro: Nova Cultural, 1999. (Os Pensadores).

WRIGHT, C. Wittgenstein on the foundations of mathematics. London: Duckworth, 1980. pt. 3, cap. 17. 